\title{
Common and distinct features of mammary tumors driven by Pten-deletion or activating Pik3ca mutation
}

\author{
Jeff C. Liu' ${ }^{1}$, Dong-Yu Wang ${ }^{2,3}$, Sean E. Egan ${ }^{4,5}$ and Eldad Zacksenhaus ${ }^{1,6}$ \\ ${ }^{1}$ Division of Advanced Diagnostics, Toronto General Research Institute - University Health Network, Toronto, Ontario, Canada \\ 2 Princess Margaret Cancer Center, Toronto, Ontario, Canada \\ ${ }^{3}$ Campbell Family Institute for Breast Cancer Research, Princess Margaret Hospital, Toronto, Ontario, Canada \\ ${ }^{4}$ Program in Developmental and Stem Cell Biology, The Hospital for Sick Children, Toronto, Ontario, Canada \\ ${ }^{5}$ Department of Molecular Genetics, University of Toronto, Toronto, Ontario, Canada \\ ${ }^{6}$ Department of Medicine, University of Toronto, Toronto, Ontario, Canada \\ Correspondence to: Jeff C. Liu, email: jeff.liu@utoronto.ca
}

Eldad Zacksenhaus, email: eldad.zacksenhaus@utoronto.ca

Keywords: PTEN, PIK3CA, breast cancer, bioinformatics, mouse models

Received: September 27,2015 Accepted: January 18,2016 Published: January 22, 2016

\section{ABSTRACT}

PTEN loss and PIK3CA activation both promote the accumulation of phosphatidylinositol $(3,4,5)$-trisphosphate (PIP3). While these proteins also have distinct biochemical functions, beyond the regulation of PIP3, little is known about the consequences of these differences in vivo. Here, we directly compared cancer signalling in mammary tumors from MMTV-Cre:Pten ${ }^{\mathrm{f} / \mathrm{f}}$ and MMTV-Cre:Pik3caLSLH1047R mice. Using unsupervised hierarchical clustering we found that whereas MMTV-Cre:Pik3CaLSL-H1047R-derived tumors fall into two separate groups, designated

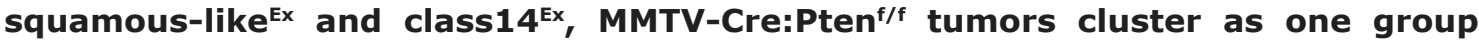
together with PIK3CA ${ }^{\mathrm{H} 1047 \mathrm{R}}$ class14 ${ }^{\mathrm{Ex}}$, exhibiting a 'luminal' expression profile. Gene Set Enrichment Analysis (GSEA) of Pten ${ }^{\Delta}$ and PIK3CA ${ }^{\mathrm{H} 1047 \mathrm{R}}$ class14 ${ }^{\mathrm{Ex}}$ tumors revealed very similar profiles of signalling pathways as well as some interesting differences. Analysis of 18 signalling signatures revealed that PI3K signalling is significantly induced whereas EGFR signalling is significantly reduced in Pten ${ }^{\Delta}$ versus PIK3CA ${ }^{{ }^{1047 R}}$ tumors. Thus, Pten ${ }^{\Delta}$ and PIK3CA ${ }^{\mathrm{H} 1047 \mathrm{R}}$ tumors exhibit discernable differences that may impact tumorigenesis and response to therapy.

\section{INTRODUCTION}

The phosphatidylinositol 3-kinase (PI3K) pathway is often induced in breast cancer through loss of the tumor suppressor Phosphatase and TENsin homolog (PTEN) or through activating mutations in PIK3CA, the catalytic subunit of PI3K [1-3]. A large body of evidence points to similar as well as distinct effects of Pten loss versus PIK3CA mutations on cancer progression and response to therapy [3-7]. Yet, a direct comparison of closely related tumors driven by alterations in these genes in a biologically relevant system is lacking.

Our laboratories have generated mice that develop mammary tumors following conditional Pten deletion or PIK3CA ${ }^{\mathrm{H} 1047 \mathrm{R}}$ mutation each induced by the same MMTVCre transgenic line $[8,9]$. Pten ${ }^{\Delta}$ tumors from MMTVCre:Pten ${ }^{\text {fff }}$ mice as well as from WAP-Cre:Pten ${ }^{\text {fff }}$ mice grouped closely with certain Wnt-Brca1-p53 tumors and with normal-like tumors, whereas PIK3CA ${ }^{\mathrm{H} 1047 \mathrm{R}}$ tumors were classified as two subtypes: squamous-like ${ }^{\mathrm{Ex}}$, and class $14^{\mathrm{Ex}}$ with a 'luminal' expression profile $[9,10]$. Here we used cluster analysis, Gene set enrichment analysis and pathway activity analysis to compare and contrast Pten $^{\perp}$ and PIK3CA ${ }^{\text {H1047R }}$ mammary tumors. Remarkably, we found that $\mathrm{Pten}^{\triangle}$ tumors cluster only with class $14^{\mathrm{Ex}}$ but not with squamous-like ${ }^{\mathrm{Ex}}$ PIK3CA $\mathrm{CA}^{\mathrm{H} 1047 \mathrm{R}}$ tumors. Furthermore, class $14^{\mathrm{Ex}}$ tumors from both models, while substantially similar in gene set expression and multiple signalling pathways, show important differences: $\mathrm{Pten}^{\Delta}$ tumors exhibit high PI3K signalling activity, whereas PIK3CA ${ }^{\mathrm{H} 1047 \mathrm{R}}$ tumors have elevated EGFR signalling. These differences may underlie tumor progression and response to therapy in $\mathrm{Pten}^{\Delta}$ versus PIK3CA ${ }^{\mathrm{H} 1047 \mathrm{R}}$ breast cancers. 


\section{RESULTS}

\section{Cluster analysis reveals that $\operatorname{Pten}^{\Delta}$ mammary tumors group together with class14 ${ }^{\mathrm{Ex}}$ PIK3CA ${ }^{\mathrm{H1047R}}$ mammary tumors}

To compare Pten $^{\Delta}$ and PIK3CA ${ }^{\mathrm{H} 1047 \mathrm{R}}$ mammary tumors by RNA profiling, we integrated microarray data from Pten $^{\Delta}$ tumors with the classifier in Ref. [10], which includes PIK3CA ${ }^{\mathrm{H} 1047 \mathrm{R}}$ mammary tumors, using Distance Weighted Discrimination (DWD) algorithm as described [9]. As expected, unsupervised hierarchical clustering grouped PIK3CA ${ }^{\text {H1047R }}$ tumors on two separate leafs denoted squamous-like ${ }^{\mathrm{Ex}}$ and class $14^{\mathrm{Ex}}$ (Figure 1). Strikingly, most $\mathrm{Pten}^{\Delta}(15 / 18)$ tumors clustered closely with the class $14^{\mathrm{Ex}}$ subset (5/12) (Figure 1; red box), and none clustered closely with the squamous-like ${ }^{\mathrm{Ex}}$ PIK3CA ${ }^{\mathrm{H} 1047 \mathrm{R}}$ tumors (Figure 1; blue box), indicating that at least using this classifier, PIK3CA ${ }^{\mathrm{H} 1047 \mathrm{R}}$ tumors show greater molecular diversity than $\operatorname{Pten}^{\Delta}$ tumors.


Figure 1: Unsupervised cluster analysis of $\operatorname{Pten}^{\Delta}$ and PIK3CA ${ }^{\mathrm{H} 1047 \mathrm{R}}$ tumors with other mouse models of breast cancer (Ref. [10]). Most Pten ${ }^{\triangle}$ tumors - derived from both MMTV-Cre:Pten ${ }^{\text {fff }}$ and WAP-Cre:Pten ${ }^{\text {fff }}$ mice - clustered with $\sim$ half of PIK3CA ${ }^{\mathrm{H} 1047 \mathrm{R}}$ tumors previously classified as class $14^{\mathrm{Ex}}$ (red box). The cluster of PIK $3 \mathrm{CA}^{\mathrm{H} 1047 \mathrm{R}}$ tumors immediately left to the red box represents squamouslike ${ }^{\mathrm{Ex}}$ tumors (blue box). 
GSEA analysis demonstrates enrichment of highly similar as well as unique gene sets in class $14^{\text {Ex }}$ Pten $^{\triangle}$ and PIK3CA ${ }^{\mathrm{H1047R}}$ mammary tumors

To identify shared and unique biological pathways that are significantly altered in tumors from MMTVCre:Pten ${ }^{\mathrm{fff}}$ and MMTV-Cre:Pik3ca ${ }^{\mathrm{LSL}-\mathrm{H} 1047 \mathrm{R}}$ mice, we performed Gene Set Enrichment Analysis (GSEA) on those that clustered together (Figure 1, red box). We first compared each tumor type to control mammary glands analyzed on the same platform, and then identified pathways that were induced or repressed in each group relative to controls. Remarkably, most altered pathways were comparably induced (red) or repressed (blue) in both $\mathrm{Pten}^{\Delta}$ and PIK3CA ${ }^{\mathrm{H} 1047 \mathrm{R}}$-driven tumors (Figure 2). These included Basal/Erbb2 Breast Cancer and Ovarian Cancer, Transcription/Translation and Mammary Stem Cell pathways that were induced, and Luminal Breast Cancer, Histone Methylation, Mitochondria and other metabolic as well as Cancer Associated pathways that were repressed (Supplemental Table 1). Thus, both tumors are more basal/less luminal, and less dependent on mitochondria, glucose, fatty acid and amino-acid metabolism relative to normal mammary glands. Notably most repressed cancer pathways are designated as "repressed in cancer", indicating that they are activated in $\operatorname{Pten}^{\Delta}$ and PIK3CA ${ }^{\mathrm{H} 1047 \mathrm{R}}$ tumors.

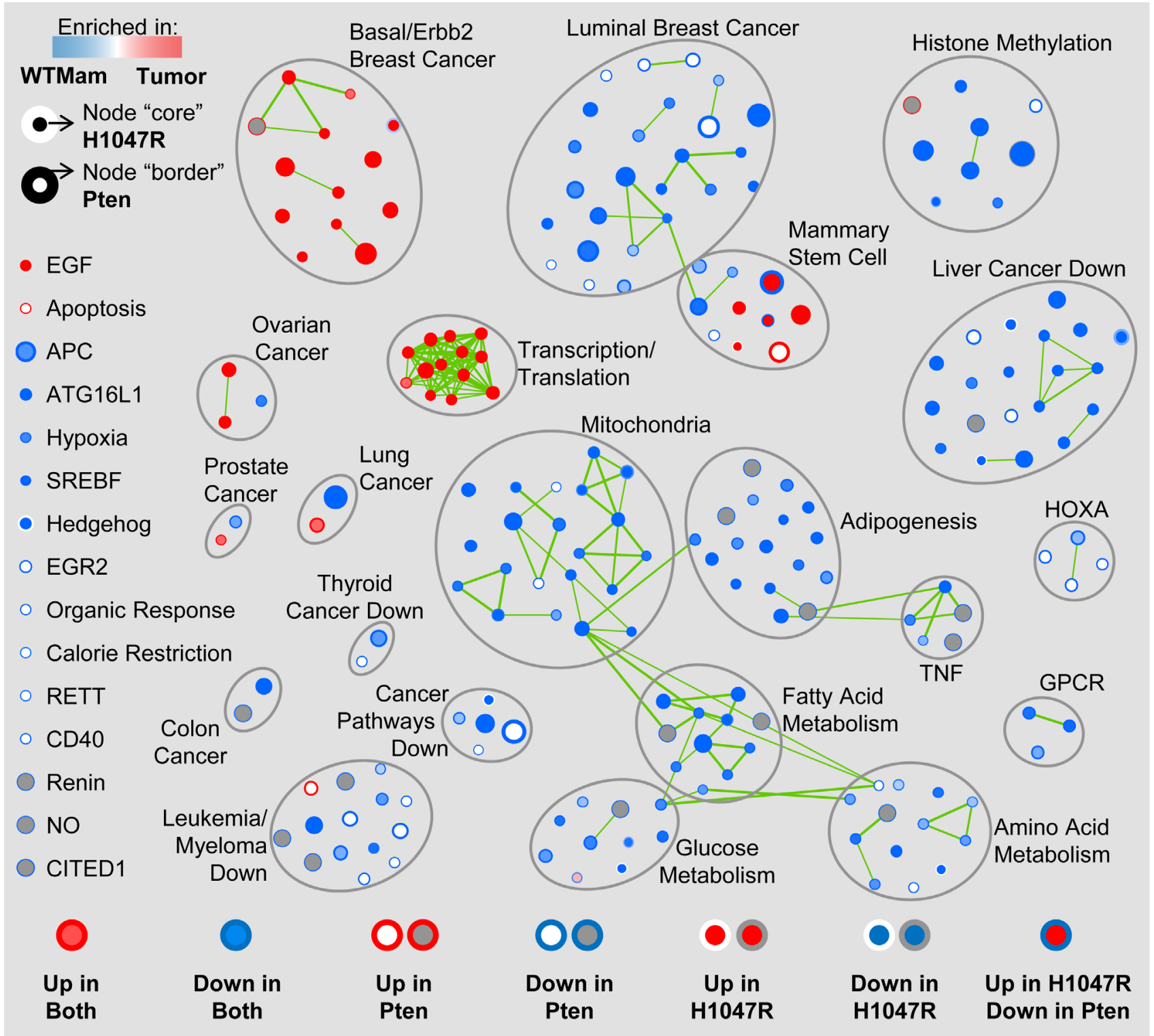

Figure 2: Gene Set Enrichment Analysis (GSEA) map of $\operatorname{Pten}^{\Delta}$ and PIK3CA ${ }^{\text {H1047R-driven class14 }}{ }^{\text {Ex }}$ tumors. Only tumors from MMTV-Cre:Pten ${ }^{\mathrm{f} / \mathrm{f}}$ and MMTV-Cre:Pik3 $\mathrm{ca}^{\mathrm{LSL}-\mathrm{H} 1047 \mathrm{R}}$ mice grouped together in Figure 1 (red box) were used in this analysis. Circles represent pathways/nodes; clusters of nodes are grouped together; green lines connecting two or more pathways/nodes in a cluster reflect shared genes. 
At the high stringent False Discovery Rate (FDR) used here $(q<0.01)$, several pathways were unique, i.e. induced or suppressed only in $\mathrm{Pten}^{\Delta}$ or only in PIK3CA ${ }^{\mathrm{H} 1047 \mathrm{R}}$-driven tumors; and 3 pathways were strongly induced in opposite directions: MCBRYAN PUBERTAL BREAST 34 WK UP - from the Basal/ Erbb2 cluster, and LIM_MAMMARY_LUMINAL_ MATURE_DN and LIM_MAMMARY_STEM_CELL_ UP from the Mammary Stem Cell cluster (Table 1; Supplemental Table 1). Overall, of 219 significant pathways in Pten $^{\Delta}$ and PIK3CA ${ }^{\text {H1047R }}$-driven tumors, 194 showed the same trend, 20 were unique (with NA/not applicable in one of the columns in Supplemental Table 1 ), and 3 were strongly contrasting. At lower stringency, $p$ $<0.05,11$ additional pathways in the opposing directions were observed (Table 1).
Pathway activity analysis reveals a significant increase in PI3K signalling in Pten $^{\Delta}$ mammary tumors and an increase in EGFR signalling in PIK3CA $^{\text {H1047R }}$ class14Ex tumors

To further dissect differences between $\operatorname{Pten}^{\Delta}$ and PIK $3 \mathrm{CA}^{\mathrm{H} 1047 \mathrm{R}}$ tumors, we determined signature activities for all 18 signalling pathways described by Gatza et al. [11]. Strikingly, only PI3K and EGFR pathways were significantly altered: the PI3K pathway was induced in Pten $^{\Delta}$ relative to PIK3CA ${ }^{\mathrm{H} 1047 \mathrm{R}}$ tumors $(P=8.72 \mathrm{E}-$ 05 by ANOVA), while EGFR signaling was induced in PIK3CA ${ }^{\mathrm{H} 1047 \mathrm{R}}$ - versus Pten $^{\Delta}$-tumors $(P=0.0048$; Figure $3)$. These differences were not only seen when comparing Pten $^{\Delta}$ to PIK3CA ${ }^{\mathrm{H} 1047 \mathrm{R}}$ class $14^{\mathrm{Ex}}$ tumors, but also when comparing Pten $^{\Delta}$ to PIK3CA ${ }^{\mathrm{H} 1047 \mathrm{R}}$ squamous-like ${ }^{\mathrm{Ex}}$ lesions (Figure 3B).

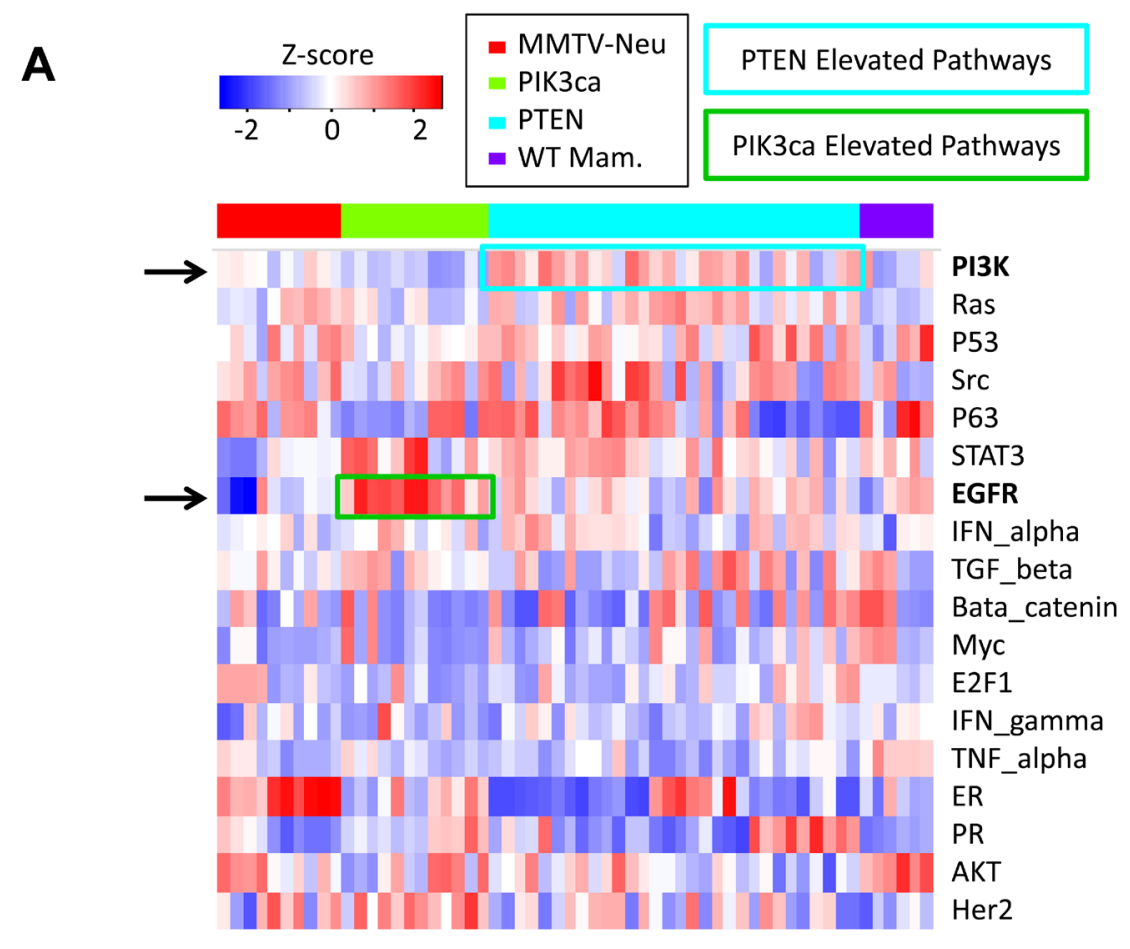

B

Tumor Pathway Activities ANOVA post hoc

\begin{tabular}{|c|ccc|c|c|}
\hline Pathways & PIK3ca-SQ & PIK3ca-14 ${ }^{\text {ex }}$ & PTEN & PTEN vs 14 & PTEN vs SQ \\
\hline PI3K & -0.52397 & -0.87424 & 0.507343 & $8.72 E-05$ & 0.000302 \\
EGFR & 1.857435 & 1.080676 & 0.109594 & 0.004832 & $5.01 E-07$ \\
\hline
\end{tabular}

Figure 3: Pathway activity analysis of 18 oncogenic signalling in Pten $^{\triangle}$ and PIK3CA ${ }^{\mathrm{H} 1047 \mathrm{R}}$-driven class14 ${ }^{\mathrm{Ex}}$ tumors. A. Pathway activities of individual samples were calculated as described by Gatza et al. [11]. Heat map of the 18 signalling pathways in Pten ${ }^{\Delta}$ and PIK3CA ${ }^{\mathrm{H} 1047 \mathrm{R}}$-tumors as well as control normal mammary glands and MMTV-Her2/Neu tumors. The differentially expressed PI3K and EGFR pathways are highlighted. B. ANOVA with Tukey post hoc analysis of Pten ${ }^{\Delta}$ tumors and the 2 subtypes of PIK $3 \mathrm{CA}^{\mathrm{H} 1047 \mathrm{R}}$ tumors, revealing a significant increase in PI3K pathway signature in Pten $^{\Delta}$ tumors, and a significant increase in EGFR signalling in PIK3CA ${ }^{\mathrm{H} 1047 \mathrm{R}}$ tumors. 
Table 1: Significantly opposing pathways by GSEA

\begin{tabular}{lcc} 
Significantly Opposing Pathways & $\begin{array}{c}\text { PIK3CA- } \\
\text { H1047R }\end{array}$ & $\begin{array}{c}\text { PTEN- } \\
\text { Loss }\end{array}$ \\
\hline MCBRYAN_PUBERTAL_BREAST_3_4WK_UP & 2.22 & -1.32 \\
LIM_MAMMARY_LUMINAL_MATURE_DOWN & 1.55 & -1.9 \\
LIM_MAMMARY_STEM_CELL_UP & 1.31 & -2 \\
LOPES_METHYLATED_IN_COLON_CANCER_DOWN & 1.8 & -1.66 \\
CHEMOKINE_ACTIVITY & 1.74 & -1.56 \\
CHEMOKINE_RECEPTOR_BINDING & 1.66 & -1.61 \\
LIU_PROSTATE_CANCER_DOWN & 1.57 & -1.69 \\
KEGG_CYTOKINE_CYTOKINE_RECEPTOR_INTERACTION & 1.4 & -1.61 \\
G_PROTEIN_COUPLED_RECEPTOR_BINDING & 1.45 & -1.51 \\
BHAT_ESR1_TARGETS_VIA_AKT1_UP & 1.31 & -1.42 \\
KARLSSON_TGFB1_TARGETS_DN & 1.31 & -1.44 \\
BOYLAN_MULTIPLE_MYELOMA_C_D_DOWN & 1.22 & -1.53 \\
REN_ALVEOLAR_RHABDOMYOSARCOMA_DOWN & 1.18 & -1.41 \\
BIOCARTA_INTRINSIC_PATHWAY & -1.48 & 1.64 \\
\hline
\end{tabular}

FDR q-value<0.01; P-value<0.05; Up/Down

mRNA expression of secreted factors involved in EGFR signalling is similar in $\operatorname{Pten}^{\Delta}$ and PIK3CA ${ }^{\text {H1047R-tumors }}$

Multiple mechanisms may account for the observed differences in PI3K and EGFR signalling between Pten $^{\Delta}$ and PIK3CA ${ }^{\text {H1047R }}$-tumors (Discussion). One possibility is suggested by a recent observation by the Arteaga group, that activating PIK3CA mutations (E545K and H1047R) in human breast cell lines alter expression of secreted proteins, cell surface receptors and ECM-interacting proteins leading to induction of EGFR signaling [12]. Of these proteins, 72 were detected in both E545K- and H1047R-over-expressing cell lines relative to controls (43 upregulated and 29 downregulated), and a fraction of these were up- or downregulated at the mRNA level [12]. We asked whether these genes are also similarly up- or down-regulated in Pten $^{\Delta}$ tumors, or whether elevated autocrine/paracrine EGFR signalling is unique to PIK3CA-driven tumors. We therefore compared the expression of these genes in mouse Pten $^{\Delta}$ versus PIK3CA $\mathrm{CA}^{\mathrm{H} 1047 \mathrm{R}}$-class $14^{\mathrm{Ex}}$ mammary tumors. In the mouse data set, 13 genes were upregulated and 16 were downregulated in the same direction as the human PIK3CA-altered proteins. Remarkably, 12 of 13 upregulated genes in $\mathrm{PIK} 3 \mathrm{CA}^{\mathrm{H} 1047 \mathrm{R}}$-tumors including integrins (ITGB4, ITGA2), laminins (LAMA3, LAMC2), FAT Tumor Suppressor Homolog 1, and peroxidasin (PXDN) were upregulated, and 9 of 16 were downregulated in $\mathrm{Pten}^{\Delta}$ tumors, with overall correlation of 0.53 $(P=0.000295)$ (Figure 4$)$. While proteomic analysis is required to confirm these observations, our results suggest that Pten loss may induce EGFR signalling as seen in human PIK3CA tumors, and therefore may not explain the differences between PIK3CA mutant and PTEN-deficient tumors.

\section{DISCUSSION}

We report that Pten-loss driven mammary tumors exhibit elevated PI3K pathway activity and reduced EGFR activity compared to PIK3CA mutant tumors. In concordance with these findings, a recent analysis of invasive lobular adenocarcinomas has demonstrated that $\mathrm{PI} 3 \mathrm{~K} / \mathrm{AKT}$ signalling is more highly elevated in PTENdeficient tumors than in PIK3CA mutants [13]. Thus, within closely related tumors driven by alterations in these genes, PTEN-loss has overtly distinct effects on cancer signalling compared to PI3K mutations. In contrast, analysis of divergent breast cancer cell lines revealed that mutations in PIK3CA but not PTEN loss coincide with increased sensitivity to mTOR inhibitors [2]. The latter report on the opposite differential sensitivity may reflect the different breast cancer subtypes in which PIK3CA mutations and PTEN loss usually occur (luminal vs. basallike, respectively), and the effect of cooperating oncogenic signalling on $\mathrm{PI} 3 \mathrm{~K} / \mathrm{PKB}-\mathrm{AKT} / \mathrm{mTOR}$ activity in the different subtypes of breast cancer. In contrast, both our results and the abovementioned study (Ref. [13]) analyzed the effects of PIK3CA mutations versus PTEN loss in closely related breast cancer subtypes, and the differences observed may truly reflect different effects these genes have on PI3K pathway activity.

A multitude of possibilities may underlie the observed differences in pathway activation. Likely, the differences reflect inherent differences in the effects of PTEN-loss vs PIK3CA mutation on breast epithelial cells. Indeed, while these proteins have opposing effects on phosphatidylinositol $(3,4,5)$-trisphosphate signaling, they 


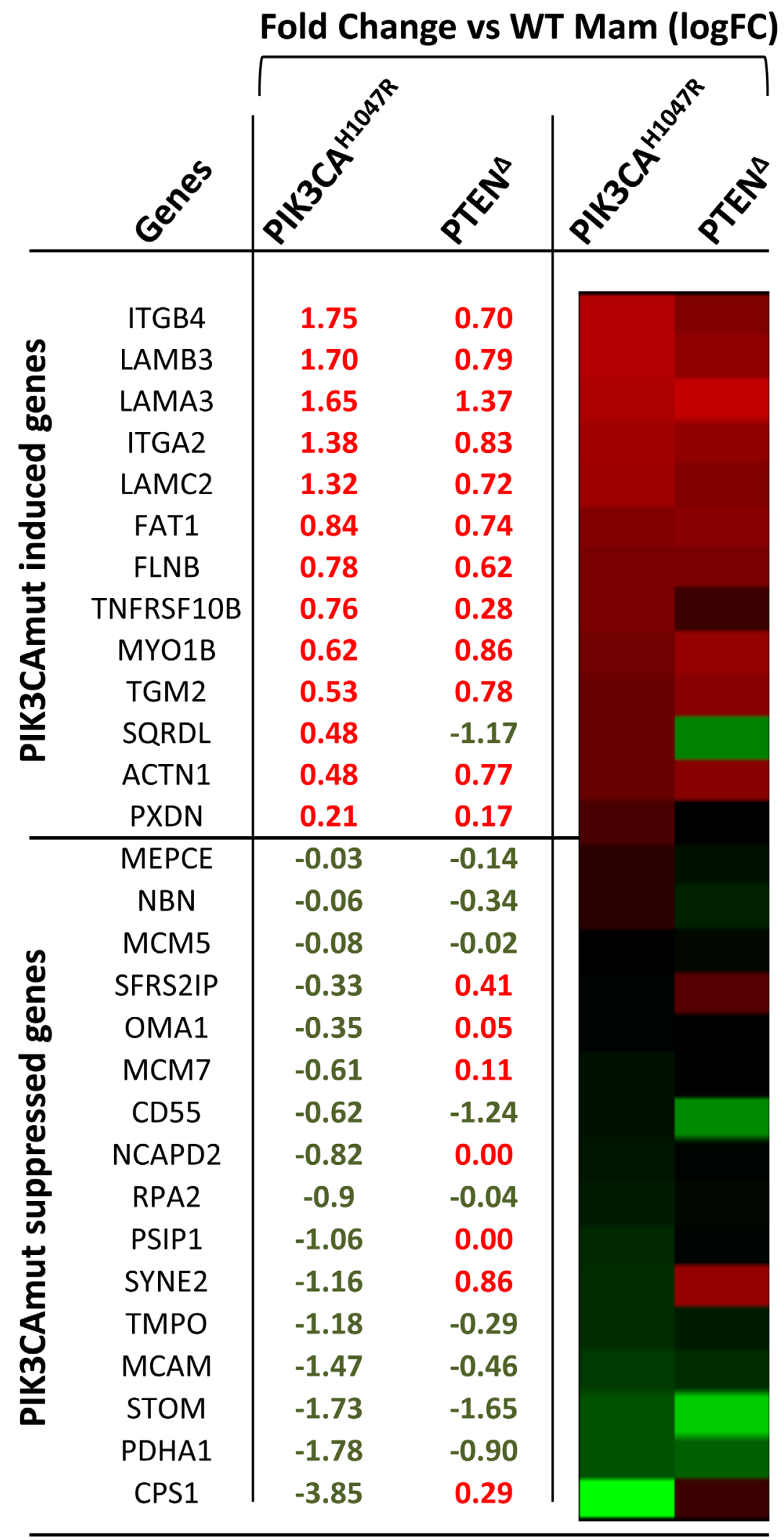

Overall Correlation (r): 0.53 ; p-value: 0.00295

Figure 4: Relative expression (values and heat map) and correlation analysis of PI3KCA-regulated genes associated with EGFR activation in Pten $^{\triangle}$ and PIK3CA ${ }^{\mathrm{H} 1047 \mathrm{R}}$ mammary tumors. 
also have additional unique functions. For example, PTEN can dephosphorylate certain proteins, and can enter and function within the nucleus in a phosphatase-independent manner or be secreted from cells to affect their neighbors [14-19]. A future challenge would be to define the unique functions of PIK3CA and PTEN underlying their differential affects on EGFR and PI3K signaling.

In conclusions, our results demonstrate that PIK3CA ${ }^{\mathrm{H} 1047 \mathrm{R}}$ induces two molecularly distinct tumor subtypes: class $14^{\mathrm{Ex}}$, which is also induced by Ptenloss, and squamous-like ${ }^{\mathrm{Ex}}$, which is uniquely induced by PIK $3 \mathrm{CA}^{\mathrm{H} 1047 \mathrm{R}}$. Within the closely related $\mathrm{Pten}^{\Delta}$ and PIK3CA ${ }^{\mathrm{H} 1047 \mathrm{R}}$ class $14^{\mathrm{Ex}}$ tumors, GSEA analysis revealed that most enriched gene sets are shared by the two tumor types, yet, some differences were noted. Using pathway signature analysis of 18 oncogenic signalling, we found that PI3K and EGFR signalling were significantly different in $\operatorname{Pten}^{\Delta}$ vs. PIK3CA ${ }^{\mathrm{H} 1047 \mathrm{R}}$ - tumors. These pathways may account for differences in drug sensitivity between Pten $^{\Delta}$ vs. PIK3CA ${ }^{\text {H1047R }}$ tumors [5]. The different response to therapy may also reflect different oncogenic events that cooperate with each gene, leading to distinct tumor subtypes in the course of cancer progression. The latter possibility is illustrated by squamous-like ${ }^{\mathrm{Ex}}$ tumors observed in PIK3CA ${ }^{\mathrm{H} 1047 \mathrm{R}}$ but not $\mathrm{Pten}^{\Delta}$ lesions (Figure 1). Moreover, in human breast cancer, PTEN-loss is most frequent in basal-like breast cancer, whereas the spectrum of PI3K mutation is wider and most frequently observed in luminal tumors [20]. Therapeutic strategies should therefore be designed with the recognition that oncogenic signalling through PIK3CA-mutation and PTEN-loss are distinct, and should be based on comprehensive mutational analysis, tumor subtyping, identification of cooperating oncogenic events and ultimately direct assessment of tumor response to anti-PI3K/AKT/mTOR and anti-RAS/ MAPK therapies.

\section{MATERIALS AND METHODS}

\section{Tumor samples and microarray analysis}

Microarray analysis with $\mathrm{PTEN}^{\Delta}$ mouse tumor models (GSE39955) and wild-type mammary glands (GSE62016) were carried out using Affymetrix Mouse Gene 1.0 ST. Microarray data were normalized using RMA method via Partek software, and log2-transformed gene expression values were obtained. Normalized expression data for tumors with PIK $3 \mathrm{CA}^{\mathrm{H} 1047 \mathrm{R}}$ mutation and corresponding wild-type mammary glands were downloaded from GSE42640.

\section{Molecular subtype classification}

"Distance Weighted Discrimination" (DWD) was used to integrate data from the mouse models with a reference dataset containing human breast cancer subtypes pre-determined by PAM50 (GSE18229). Unsupervised hierarchical clustering (complete linkage) with the intrinsic genes signature (Herschkowitz et al, 2007) was used to group tumor samples for subtype classification.

\section{Gene set enrichment analysis}

Differential gene expressions comparing: 1) PIK3CA ${ }^{\mathrm{H} 1047 \mathrm{R}}$ vs WT mammary glands; and 2) $\mathrm{PTEN}^{\Delta}$ vs WT mammary glands; were calculated by Moderate $\mathrm{T}$ test using limma package in R. Genes were ordered using the $\mathrm{t}$-values corresponding to each pair-wise comparison as rank files for Gene Set Enrichment Analysis (GSEA, [21] with 1000 permutations and gene-sets size between 8 and 500. The gene-sets included in the GSEA analyses were obtained from KEGG, MsigDB-c2, NCI, Biocarta, IOB, Netpath, Human Cyc, Reactome and the Gene Ontology (GO) databases, updated March 2012 (http://baderlab.org/ GeneSets). An enrichment map (version 1.2 of Enrichment Map software [22] was generated for each comparison using enriched gene-sets with a nominal $p$-value $<0.05$ and the overlap coefficient set to 0.5 as described $[23,24]$.

\section{Pathway activities}

Pathway activities of individual samples were calculated from microarray data as described [11], and normalized by z-score. Heat map was generated by the function heatmap. 2 in gplots package in R. ANOVA with Tukey post hoc was used to determine the significance of differences between $\operatorname{Pten}^{\Delta}$ tumors and the 2 subtypes of PIK $3 C^{\mathrm{H} 1047 \mathrm{R}}$ tumors, squamous-like and class $14^{\mathrm{EX}}$.

\section{Statistic analysis}

Correlation analysis was performed comparing $\operatorname{logFC}\left(\log 2\right.$ of fold change) values of PIK $3 \mathrm{CA}^{\mathrm{H} 1047 \mathrm{R}}$ vs WT mammary glands with values of $\mathrm{PTEN}^{\Delta}$ vs WT mammary glands by the function corr.test in psych package in $\mathrm{R}$ that calculates both the correlation coefficient (r) and significance ( $p$-value).

\section{ACKNOWLEDGMENTS}

Funding for this project was provided by the Canadian Breast Cancer Foundation (CBCF, Ontario) and Canadian Cancer Society Research Institute (CCSRI) to EZ as well as the Terry Fox Foundation to SEE and EZ. 


\section{CONFLICTS OF INTEREST}

The authors declare no conflict of interest.

\section{REFERENCES}

1. Cully M, You H, Levine AJ and Mak TW. Beyond PTEN mutations: the PI3K pathway as an integrator of multiple inputs during tumorigenesis. Nature reviews Cancer. 2006; 6:184-192.

2. Adams JR, Schachter NF, Liu JC, Zacksenhaus E and Egan SE. Elevated PI3K signaling drives multiple breast cancer subtypes. Oncotarget. 2011; 2:435-447. doi: 10.18632/ oncotarget.285.

3. Davis NM, Sokolosky M, Stadelman K, Abrams SL, Libra M, Candido S, Nicoletti F, Polesel J, Maestro R, D'Assoro A, Drobot L, Rakus D, Gizak A, Laidler P, DulinskaLitewka J, Basecke J, et al. Deregulation of the EGFR/ $\mathrm{PI} 3 \mathrm{~K} / \mathrm{PTEN} / \mathrm{Akt} / \mathrm{mTORC} 1$ pathway in breast cancer: possibilities for therapeutic intervention. Oncotarget. 2014; 5:4603-4650. doi: 10.18632/oncotarget.2209.

4. Yuan TL and Cantley LC. PI3K pathway alterations in cancer: variations on a theme. Oncogene. 2008; 27:54975510 .

5. Weigelt B, Warne PH and Downward J. PIK3CA mutation, but not PTEN loss of function, determines the sensitivity of breast cancer cells to mTOR inhibitory drugs. Oncogene. 2011; 30:3222-3233.

6. Stambolic V. Cancer: Precise control of localized signals. Nature. 2015; 522:38-40.

7. Wheler JJ, Moulder SL, Naing A, Janku F, Piha-Paul SA, Falchook GS, Zinner R, Tsimberidou AM, Fu S, Hong DS, Atkins JT, Yelensky R, Stephens PJ and Kurzrock R. Anastrozole and everolimus in advanced gynecologic and breast malignancies: activity and molecular alterations in the PI3K/AKT/mTOR pathway. Oncotarget. 2014; 5:30293038. doi: 10.18632/oncotarget. 1799 .

8. Adams JR, Xu K, Liu JC, Agamez NM, Loch AJ, Wong RG, Wang W, Wright KL, Lane TF, Zacksenhaus E and Egan SE. Cooperation between Pik3ca and p53 mutations in mouse mammary tumor formation. Cancer research. 2011; 71:2706-2717.

9. Liu JC, Voisin V, Wang S, Wang DY, Jones RA, Datti A, Uehling D, Al-awar R, Egan SE, Bader GD, Tsao M, Mak TW and Zacksenhaus E. Combined deletion of Pten and p53 in mammary epithelium accelerates triple-negative breast cancer with dependency on eEF2K. EMBO molecular medicine. 2014; 6:1542-1560.

10. Pfefferle AD, Herschkowitz JI, Usary J, Harrell JC, Spike BT, Adams JR, Torres-Arzayus MI, Brown M, Egan SE, Wahl GM, Rosen JM and Perou CM. Transcriptomic classification of genetically engineered mouse models of breast cancer identifies human subtype counterparts. Genome biology. 2013; 14:R125.
11. Gatza ML, Lucas JE, Barry WT, Kim JW, Wang Q, Crawford MD, Datto MB, Kelley M, Mathey-Prevot B, Potti A and Nevins JR. A pathway-based classification of human breast cancer. Proc Natl Acad Sci U S A. 2010; 107:6994-6999.

12. Young $\mathrm{CD}$, Zimmerman LJ, Hoshino D, Formisano L, Hanker AB, Gatza ML, Morrison MM, Moore PD, Whitwell CA, Dave B, Stricker T, Bhola NE, Silva GO, Patel P, Brantley-Sieders DM, Levin M, et al. Activating PIK3CA Mutations Induce an Epidermal Growth Factor Receptor (EGFR)/Extracellular Signal-regulated Kinase (ERK) Paracrine Signaling Axis in Basal-like Breast Cancer. Molecular \& cellular proteomics. 2015; 14:19591976.

13. Ciriello G, Gatza ML, Beck AH, Wilkerson MD, Rhie SK, Pastore A, Zhang H, McLellan M, Yau C, Kandoth C, Bowlby R, Shen H, Hayat S, Fieldhouse R, Lester SC, Tse GM, et al. Comprehensive Molecular Portraits of Invasive Lobular Breast Cancer. Cell. 2015; 163:506-519.

14. Shi Y, Wang J, Chandarlapaty S, Cross J, Thompson $\mathrm{C}$, Rosen $\mathrm{N}$ and Jiang $\mathrm{X}$. PTEN is a protein tyrosine phosphatase for IRS1. Nature structural \& molecular biology. 2014; 21:522-527.

15. Song MS, Salmena L and Pandolfi PP. The functions and regulation of the PTEN tumour suppressor. Nature reviews Molecular cell biology. 2012; 13:283-296.

16. Bassi C, Ho J, Srikumar T, Dowling RJ, Gorrini C, Miller SJ, Mak TW, Neel BG, Raught B and Stambolic V. Nuclear PTEN controls DNA repair and sensitivity to genotoxic stress. Science. 2013; 341:395-399.

17. Zhang S, Huang WC, Li P, Guo H, Poh SB, Brady SW, Xiong Y, Tseng LM, Li SH, Ding Z, Sahin AA, Esteva FJ, Hortobagyi GN and $\mathrm{Yu}$ D. Combating trastuzumab resistance by targeting SRC, a common node downstream of multiple resistance pathways. Nat Med. 2011; 17:461469.

18. Song MS, Carracedo A, Salmena L, Song SJ, Egia A, Malumbres M and Pandolfi PP. Nuclear PTEN regulates the APC-CDH1 tumor-suppressive complex in a phosphataseindependent manner. Cell. 2011; 144:187-199.

19. Hopkins BD, Fine B, Steinbach N, Dendy M, Rapp Z, Shaw J, Pappas K, Yu JS, Hodakoski C, Mense S, Klein J, Pegno S, Sulis ML, Goldstein H, Amendolara B, Lei L, et al. A secreted PTEN phosphatase that enters cells to alter signaling and survival. Science. 2013; 341:399-402.

20. Network TCGA. Comprehensive molecular portraits of human breast tumours. Nature. 2012; 490:61-70.

21. Subramanian A, Tamayo P, Mootha VK, Mukherjee S, Ebert BL, Gillette MA, Paulovich A, Pomeroy SL, Golub TR, Lander ES and Mesirov JP. Gene set enrichment analysis: a knowledge-based approach for interpreting genome-wide expression profiles. Proc Natl Acad Sci U S A. $2005 ; 102: 15545-15550$.

22. Merico D, Isserlin R, Stueker O, Emili A and Bader GD. 
Enrichment map: a network-based method for gene-set enrichment visualization and interpretation. PLoS One. 2011; 5:e13984.

23. Liu JC, Egan SE and Zacksenhaus E. A Tumor initiating cell-enriched prognostic signature for HER2+:ERalphabreast cancer; rationale, new features, controversies and future directions. Oncotarget. 2013; 4:1317-1328. doi: 10.18632/oncotarget.1170.

24. Liu JC, Voisin V, Bader GD, Deng T, Pusztai L, Symmans WF, Esteva FJ, Egan SE and Zacksenhaus E. Seventeengene signature from enriched Her2/Neu mammary tumor-initiating cells predicts clinical outcome for human HER2+:ERalpha- breast cancer. Proceedings of the National Academy of Sciences of the United States of America. 2012; 109:5832-5837. 